E3S Web of Conferences 1, 23004 (2013)

DOI: $10.1051 / \mathrm{e} 3$ sconf/20130123004

(C) Owned by the authors, published by EDP Sciences, 2013

\title{
A comparison of recent methods for modelling mercury fluxes at the air- water interface
}

\author{
L. Fantozzi $^{1}$, G. Manca ${ }^{1}$ and F. Sprovieri ${ }^{1}$ \\ ${ }^{1}$ CNR-Institute of Atmospheric Pollution Research, Rende, ITALY, I.fantozzi@iia.cnr.it
}

\begin{abstract}
The atmospheric pathway of the global mercury flux is known to be the primary source of mercury contamination to most threatened aquatic ecosystems. Notwithstanding, the emission of mercury from surface water to the atmosphere is as much as $50 \%$ of total annual emissions of this metal into the atmosphere. In recent years, much effort has been made in theoretical and experimental researches to quantify the total mass flux of mercury to the atmosphere. In this study the most recent atmospheric modelling methods and the information obtained from them are presented and compared using experimental data collected during the Oceanographic Campaign Fenice 2011 (25 October - 8 November 2011), performed on board the Research Vessel (RV) Urania of the CNR in the framework of the MEDOCEANOR ongoing program. A strategy for future numerical model development is proposed which is intended to gain a better knowledge of the long-term effects of meteo-climatic drivers on mercury evasional processes, and would provide key information on gaseous $\mathrm{Hg}$ exchange rates at the air-water interface.
\end{abstract}

Key words: Mercury cycle, air-water flux, gas-exchange model

\section{Introduction}

Mercury is one of "priority pollutants", as its mobility between the hydrosphere and the atmosphere threatens the biosphere globally. Air-water elemental mercury ( $\mathrm{Hg} 0)$ flux estimations, based on the two-layer gas exchange model, are significantly affected by the choice of gas transfer parameterizations (Rolfhus and Fitzgerald, 2001; Andersson et al., 2007; Kuss et al., 2009, Ci et al., 2011). Therefore, the value of the evasion of mercury from the sea surface can vary significantly in depending of the use of different types of calculation.

In this study, two different methods for modelling mercury fluxes at the air-water interface have been compared using experimental data collected during the Oceanographic Campaign Fenice 2011 (25 October - 8 November 2011), on board the Research Vessel (RV) Urania of the CNR in the framework of the MEDOCEANOR ongoing program (Sprovieri et al., 2010). We propose an integration of the most recent methods for calculate mercury flux, that seems to be more reliable for mercury.

\section{Materials and Methods}

Fluxes of elemental mercury at the air-water interface were calculated using two methods: the Johnson scheme (Johnson, 2010) and the Wanninkhof parameterization (Wanninkhof, 1992). The Johnson scheme was integrated with the following new equation for the mercury diffusion coefficient in water, described in Kuss (2009):

$\mathrm{D}_{\mathrm{Hg}}\left[\mathrm{cm}^{2} \mathrm{~s}^{-1}\right]=0.02293 * \operatorname{EXP}\left(17.76 * 1000 /\left(8.314 * \mathrm{~T}_{\mathrm{w}}\right)\right)$

where $\mathrm{T}_{\mathrm{w}}$ is the water temperature in Kelvin.

\section{Results and Discussion}

Fig. 1 shows the relationship between the elemental mercury ( $\mathrm{Hg} 0)$ flux estimated, for the first time, following the scheme proposed in Johnson (2010), and the $\mathrm{Hg} 0$ flux calculated according to the Wanninkhof (1992) parameterization of the mass transfer coefficient $(\mathrm{Kw})$. This last parameterization has been currently used in mercury emission estimations (Gårdfeldt et al., 2003; Ci et al., 2011; Conaway et al, 2003; Rholfus and Fitzgerald, 2001; Wängberg et al., 2001). The mercury flux estimated following the scheme of Johnson (2010) results to be significantly lower than that estimated following the parameterization proposed by Wanninkhof (1992). The main difference between the two 
parameterizations is the equation for $\mathrm{Kw}$. Moreover we integrated the Johnson scheme with a new equation to estimate the mercury diffusion coefficient $\left(\mathrm{D}_{\mathrm{Hg}}\right)$ described in Kuss et al. (2009) and based on molecular dynamics simulations. This equation seems to be more reliable for small and heavy atoms (i.e., $\mathrm{Hg} 0$ ) because is based on experimental measurements as opposed to other methods such as the Wilke-Chang method (Wilke and Chang, 1955) and mass-based approximation (Schroeder et al., 1992). The parametrization proposed by Wanninkhof (1992), uses $\mathrm{D}_{\mathrm{Hg}}$ estimation according to Wilke and Chang (1995).

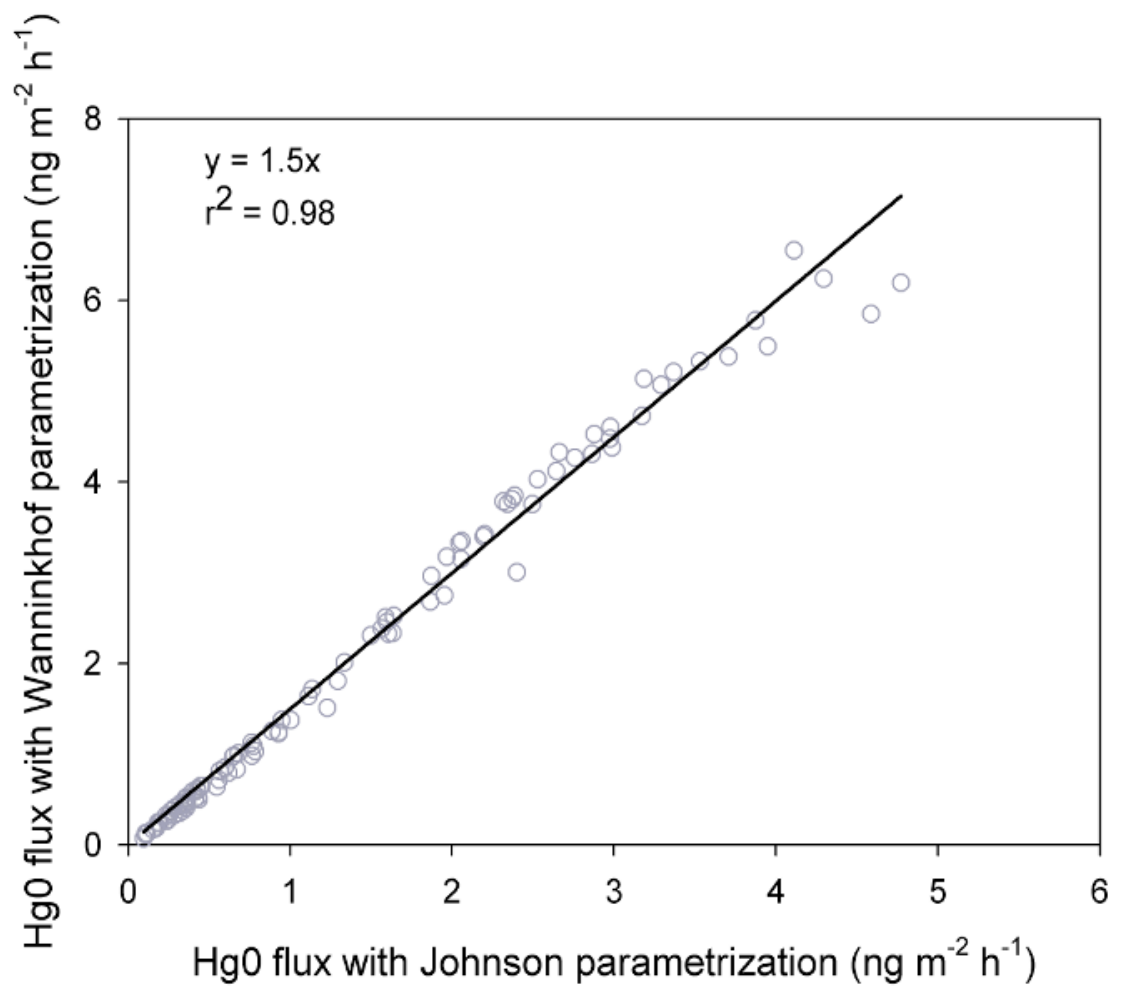

Fig. 1. Hg0 fluxes estimated according to Wanninkhof (1992) and Johnson (2010) parameterizations
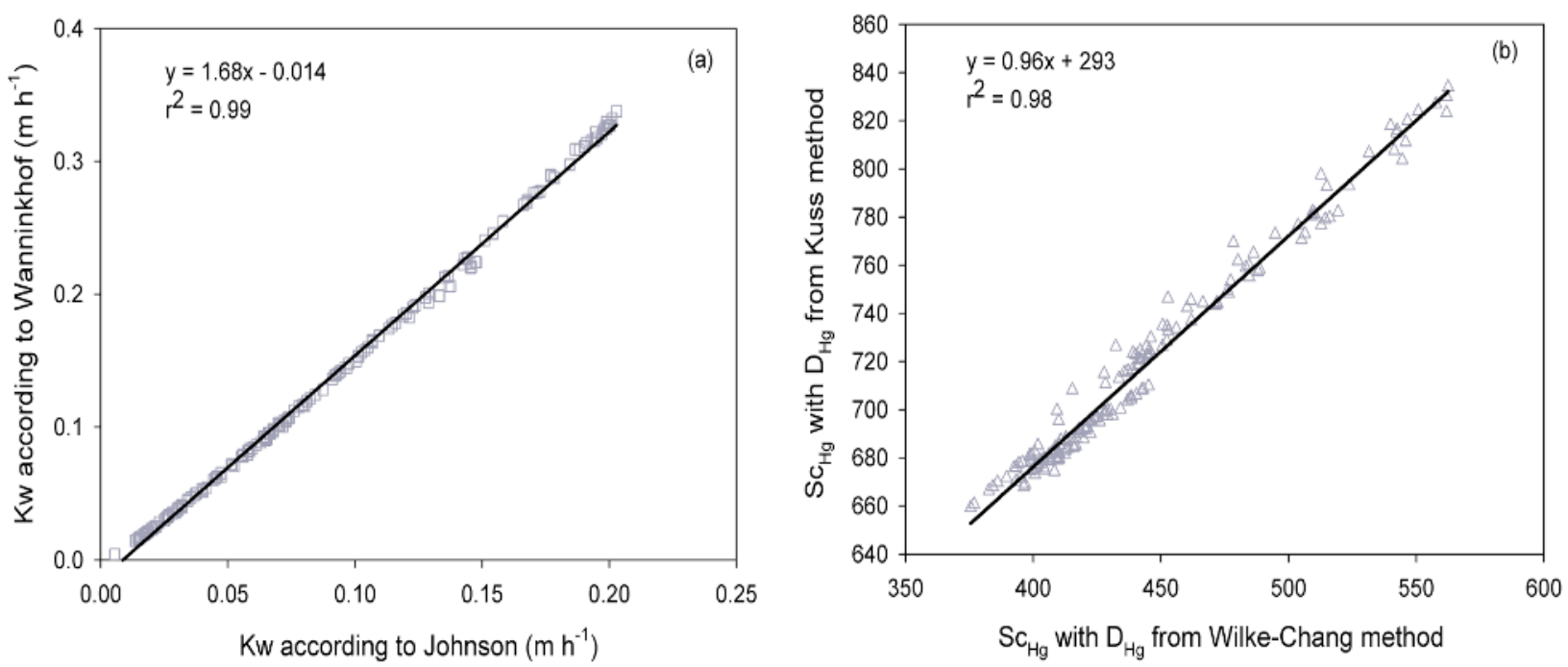

Fig. 2. (a) Mass transfer coefficient (Kw) estimated with Wanninkhof (1992) and Johnson (2010) parameterizations. (b) Schmidt number for $\mathrm{Hg0}$ estimated using the Wilke and Chang (1995) and Kuss (2009) equations for the aqueous diffusion coefficient of $\mathrm{Hg} 0$. 
Fig 2(a) shows that the values of Kw, estimated using the equation of Kuss (2009) for $\mathrm{D}_{\mathrm{Hg}}$ with the Johnson scheme, are lower than the values based on the WilkeChang equation used in the Wanninkhof parameterization (Wanninkhof, 1992). The $\mathrm{D}_{\mathrm{Hg}}$ values affect directly the Schmidt number for $\mathrm{Hg} 0$ since it is inversely proportional to $\mathrm{D}_{\mathrm{Hg}}$. It means that the higher the value of $\mathrm{D}_{\mathrm{Hg}}$ the lower the value of the Schmidt number. In Fig. 2(b) is reported the relationship between the Schmidt number calculated with the $\mathrm{D}_{\mathrm{Hg}}$ from Kuss (2009) and $\mathrm{D}_{\mathrm{Hg}}$ from Wilke and Chang (1995). Using the Kuss equation for $\mathrm{D}_{\mathrm{Hg}}$ we obtain values of Schmidt number that are $60 \%$ higher than those estimated with the Wilke-Chang equation for $\mathrm{D}_{\mathrm{Hg}}$. Hence, changes in the oceanic $\mathrm{HgO}$ emission budget resulting from calculations incorporating the new $\mathrm{D}_{\mathrm{Hg}}$ are expected to be significant.

\section{Conclusion}

Air-water $\operatorname{Hg}(0)$ flux estimations, based on the two-layer gas exchange model, are significantly affected by the choice of gas transfer parameterizations (Rolfhus and Fitzgerald, 2001; Andersson et al., 2007; Kuss et al., 2009, Ci et al., 2011).

The air-water gas transfer of elemental mercury (Hg0) is controlled by its diffusion through the water-side boundary layer and thus by its diffusion coefficient, $\mathrm{DHg}$, the value of which is discussed in this work.

In this study we propose a numerical scheme for estimating the $\operatorname{Hg}(0)$ fluxes at the air-water interface that is based on a two-phase model, a model with a parameterization based on the most recent experimental findings: the Johnson scheme (Johnson, 2010) integrated with a new equation to estimate the mercury diffusion coefficient $\left(\mathrm{D}_{\mathrm{Hg}}\right)$ described in Kuss et al. (2009). This equation seems to be more reliable for elemental mercury because is based on experimental measurements.

Our results suggest that the incorporation of the $\mathrm{D}_{\mathrm{Hg}}$ from Kuss (2009) into the model leads to lower estimates of mercury emissions. This achievement is an important step toward a better understanding of the global cycle of atmospheric mercury.

\section{References}

Andersson ME, Gardfeldt K, Wangberg I, Sprovieri F, Pirrone N, Lindqvist O. Seasonal and daily variation of mercury evasion at coastal and off shore sites from the Mediterranean Sea. Mar Chem 2007; 104:214-226.

Ci Z, Zhang X, Wang Z. Elemental mercury in coastal seawater of Yellow Sea, China: Temporal variation and air-sea exchange Atmos Environ 2011; 45:183190.

Conaway CH, Squire S, Mason RP, Flegal AR. Mercury speciation in the San Francisco Bay estuary. Mar Chem 2003; 80:199-225.

Wanninkhof R. Relationship between wind speed and gas exchange over the ocean. J Geophys Res 1992; 97(C5):7373-7382.

Gårdfeldt K, Sommar J, Ferrara R, Ceccarini C, Lanzillotta E, Munthe J, Wängberg I, Lindqvist O, Pirrone N, Sprovieri F, Pesenti E, Strömberg D. Evasion of mercury from coastal and open waters of the Atlantic Ocean and Mediterranean Sea. Atmos Environ 2003; 37(Supplement 1):73-84.

Johnson MT. A numerical scheme to calculate temperature and salinity dependent air-water transfer velocities for any gas. Ocean Sci 2010; 6:913-932.

Kuss J, Holzmann J, Ludwig AR. Coefficient for natural waters determined by molecular dynamics simulation. Environ Sci Technol 2009; 28:31833186.

Rolfhus KR, Fitzgerald WF. The evasion and spatial/temporal distribution of mercury species in Long Island Sound, CT-NY. Geochim et Cosmochim Acta 2001; 65: 407-418.

Schroeder W, Lindqvist O, Munthe J, Xiao Z. Volatilization of mercury from lake surfaces. Sci Total Environ 1992; 125:47-66.

Sprovieri, F., Pirrone, N., Ebinghaus, R., Kock, H., and Dommergue, A.: A review of worldwide atmospheric mercury measurements. Atmos. Chem. Phys. 10, 8245-8265, 2010.

Wängberg I, Schmolke S, Schager P, Munthe J, Ebinghaus R, Iverfeldt A. Estimates of air-sea exchange of mercury in the Baltic Sea. Atmos Environ 2001; 35(32):5477-5484.

Wilke CR, Chang P. Correlation of diffusion coefficients in dilute solutions. AIChE J. 1955; 1(2):264-270. 